\title{
Synthetic Genres of Art as the Sources of Russian Catchword Units Fund Enrichment
}

\section{Shulezhkova Svetlana Grigorjevna ${ }^{1}$}

Professor, Nosov Magnitogorsk State Technical University, Magnitogorsk, Russia.

\section{Diadechko Ludmila Petrovna ${ }^{2}$}

Professor, Taras Shevchenko National University of Kiev, Kiev, Ukraine.

(date of receiving: February, 2018; date of acceptance: May, 2018)

\begin{abstract}
In the second half of the $20^{\text {th }}$ and the beginning of the $21^{\text {st }}$ centuries are marked by the process of Russian catchword units fund updating. Contrary to globalization, it occurs mainly at the expense of internal forces of the language system. Russian society endures cardinal changes in the sphere of culture: from literature-centric it progressively becomes the culture of performance. In the $18^{\text {th }}-19^{\text {th }}$ centuries, verbal sources were the main suppliers of new catchwords, but now synthetic styles and genres of art play a leading part in the process of catchword enrichment of Russian language. Animated films hold a specific place among them. Animated cinema appeared in Russia more than 100 years ago, and by the $1970 \mathrm{~s}-1980 \mathrm{~s}$, it has achieved brilliant results. Catchwords from the Soviet cartoons of those years are still widely used. Tens of catchwords from modern Russian cartoons, translated into many languages, have joined them. Their linguocultural description is the work of the future. The article authors offer one of the possible solutions to this difficult task.
\end{abstract}

Keywords: Catchword Unit, Language System, Synthetic Genres of Art, Centrist Culture Spectacle.

1. E-mail: shulezkova@gmail.com

2. E-mail: eptonim@ukr.net 


\section{Синтетические жанры искусства как источники обогащения фонда крылатых единиц современного русского языка}

\section{ШШулежкова Светлана Григорьевна ${ }^{1}$}

Профессор, Магнитогорский государственный технический университет им.

Г.И. Носова,

Магнитогорск, Россия.

\section{Дядечко Людмила Петровна ${ }^{2}$}

Профессор, Киевский национальный университет им. Т.Г. Шевченко, Киев, Украина.

(дата получения: февраль 2018 г.; дата принятия: май 2018 г.)

\section{Аннотация}

Во второй половине XX - начале XXI в. активизировался процесс обновления фонда крылатых единиц (КЕ) русского языка. Вопреки глобализации, он происходит преимущественно за счёт внутренних резервов языковой системы. Российское общество переживает кардинальные изменения в сфере культуры: из литературоцентристской она неуклонно превращается в культуру зрелищецентристскую. И если в XVIII-XIX вВ. основными источниками новых КЕ были вербальные источники, то сейчас всё бо́льшую роль в обогащении русского языка образными словами и выражениями играют синтетические виды и жанры искусства. Особое место среди них занимает мультипликационный кинематограф. В России он зародился более 100 лет тому назад и уже к 1970-1980-м гг. достиг блестящих результатов. $\mathrm{KE}$ из советских мультфильмов тех лет широко используются и сегодня. К ним присоединились десятки КЕ из современных переведённых на многие языки мира мультфильмов России. Лингвокультурологическое их описание - дело будущего. Авторы статьи предлагают один из возможных путей решения этой непростой задачи.

Ключевые слова: Крылатая Единица, Языковая Система, Синтетические Жанры Искусства, Зрелище Центристская Культура.

1. E-mail: shulezkova@gmail.com

2. E-mail: eptonim@ukr.net 


\section{Введение}

Фонд крылатых единиц (КЕ) - один из самых мобильных пластов лексикофразеологической системы любого живого, естественного языка. Он неразрывно связан с состоянием культуры народа и с теми социальными, экономическими, геополитическими, конфессиональными и информационнотехническими процессами, которые вызывают изменения в менталитете носителей языка, в их этических взглядах и эстетических пристрастиях. КЕ, наряду с другими языковыми знаками, отмеченными лингвокультурной значимостью, выступают в роли элементов «особого кода - кода национальной культуры» (Душенко 1999. 53), ибо значение любой КЕ обогащено специфическим фоном - памятью о собственных «корнях», об обстоятельствах, вызвавших её к жизни. Связь с автором или произведениемисточником расширяет рамки значения КЕ дополнительными ассоциациями, обеспечивают ей определённый эмоциональный настрой, помогает вызвать у собеседника, принадлежащего к той же культуре, нужную реакцию.

В последней трети XIX - начале XX столетия в фонде крылатых единиц русского языка начинают происходить кардинальные изменения. С одной стороны, они были следствием великих потрясений, которые пережила Россия: кровопролитная русско-турецкая война, закончившаяся освобождением Болгарии от османского ига; поражение в Первой мировой войне, в которой погибли сотни тысяч русских солдат и офицеров, а страна лишилась значительных территорий; Октябрьская социалистическая революции 1917 г., вылившаяся в гражданскую войну и повлекшая за собой коренную перестройку социально-экономической жизни государства. С другой стороны, трансформировалась и сама русская национальная культура. Если до 1870-х гг. основными поставщиками крылатых слов (КС) и крылатых выражений (КВ) русского языка были художественные произведения отечественных и зарубежных писателей и поэтов, то к концу XIX в. активизация протестных 
движений повлекла за собой рождение КС и КВ из публицистических (социалдемократических и коммунистических) текстов и из революционных рабочих песен. Кроме того, изобретение записывающих, тиражирующих и воспроизводящих устройств способствовало превращению оперы, оперетты, романса, кинематографа, а также других профессиональных жанров искусства, наряду с песней, народной и авторской, в источники КЕ наряду с литературой. Поддержанные средствами массовой коммуникации, в XX синтетические виды искусства стали играть лидирующую роль в пополнении фонда КЕ русского языка.

\section{Основная часть}

Языковые процессы XX - начала XXI в. отражают смену литературоцентристского типа культуры зрелищецентристским. Однако большинство составителей словарей и справочников КЕ по традиции акцентировали своё внимание на КС и КВ, восходящих к вербальным видам искусства. В качестве авторов оперных, романсных и песенных КЕ в справочниках и словарях обычно указывались создатели поэтических текстов, ибо невербальные виды искусства рассматривались, по преимуществу, как посредники в освоении КЕ. ЭТот подход к описанию КС и КВ отразился в высокопрофессионально выполненном, неоднократно переиздававшемся словаре «Крылатые слова. Литературные цитаты, образные выражения» (Ашукины. 1955, 1960, 1966, 1986, 1987) и в последующих многочисленных эптографических трудах, авторы которых опирались на перечень единиц Н.С. и М.Г. Ашукиных. К 1990-м гг. прошлого века в русском языке функционировало уже около $1000 \mathrm{KE}$, восходящих к синтетическим жанрам искусства, но в словари, нацеленные не просто на фиксацию новых КЕ, а на полноценное их лингвистическое описание, до конца XX и первых лет XXI в. они попадали очень дозированно. Исключением в этом отношении можно 
считать лишь отдельные работы первой половины 1990-х и начала 2000-х гг., каждая из которых рассматривалась в качестве подготовительной к будущим полноценным эптологическим изданиям. К ним примыкает «Словарь крылатых выражений из области искусства», где подробному лингвокультурологическому анализу подвергается около $1000 \mathrm{KE}$, восходящих к песням, романсам, кинофильмам операм, опереттам, речевым жанрам эстрады, телевизионным постановкам и т. д. (Шулежкова. 2003).

Анимационные короткометражки в России появились ещё в первое десятилетие XX столетия. В 1906 г. балетмейстер Мариинского театра А. Ширяев, друг знаменитого хореографа Мариуса Петипа, создал кукольный мультфильм с двенадцатью танцующими фигурками. За этим фильмом последовали ещё три, выполненных аналогично для учебных целей (Ксензенко. 2009). Мультипликация укрепляла свои позиции в 1920 - 1950-е годы; она привлекала внимание многих отечественных деятелей культуры (В. Маяковского, С. Эйзенштейна и др.), которые понимали широчайшие возможности этого нового вида искусства. Однако долгое время отношение к анимационному творчеству в целом в стране было снисходительным. Как пишет один из самых основательных исследователей мультипликации С. Асенин, «Мультипликацию не только “затирал” кинопрокат, считавший демонстрацию мультфильмов финансово невыгодной; не менее надменно, сверху вниз, как на что-то детски игрушечное, ненастоящее, третьесортное, смотрели нередко на неё деятели "большого" кино, её пренебрежительно обходила молчанием критика» (Асенин 1974. 4). Прошло более сорока лет после того, как были написаны эти строки, а с отголосками подобного отношения к мультфильмам можно столкнуться и в наше время. Так, например, фундаментальный том под названием «Большой словарь: Крылатые фразы отечественного кино» (Кожевников 2001), в котором представлены цитаты из 1305 отечественных художественных фильмов, появившихся на 
российских экранах в 1931-2000 гг., не содержит ни одной цитаты из мультфильмов, да и сами мультфильмы как источники крылатых фраз вообще автором не упоминаются.

Мультипликация - молодое синтетическое искусство. В ней «образный строй, сила художественного воздействия $<\ldots>$ основаны главным образом на выразительности движения, на метафоре и гиперболе, символике и олицетворении $<\ldots>$ для неё характерны иносказание и та масштабная типизация, то сгущение наиболее существенных черт и признаков, которые наиболее тесным образом связаны $<\ldots>$ с многовековым опытом и реалистическими традициями народного опыта» (Асенин 1974. 9). Эти достоинства в полной мере проявились в советском анимационном искусстве 1960 - 1980-х гг., когда оно достигло наивысшего расцвета.

Язык сразу же отреагировал на успехи мультипликации. В разговорной речи не только детей, но и взрослых - пап и мам, бабушек и дедушек - то и дело зазвучали забавные реплики полюбившихся персонажей из мультфильмов: Кажется, дождь начинается; Деньги у нас есть. У нас ума не хватает; Пустяки, дело житейское; Поели - можно поспать. Поспали можно поесть; Спокойствие, только спокойствие; и пр. Общая демократизация русского языка в постсоветскую эпоху способствовала проникновению этих оборотов в публицистику, в художественные тексты, на эстраду, в различные СМИ; мгновенно подхватили «мультяшные» цитаты пользователи Интернета. Так, например, любимая фраза Бабы Яги, героини мультфильма «Баба Яга против» (1980), которая всячески препятствует медвежонку Мише попасть в Москву на Олимпиаду, стала употребляться по отношению к тем, кто никогда ни с чем не соглашается:

А Баба Яга протие! [В тексте:] Есть люди, которые вне зависимости от своей способности к объективной оџенке ситуации, события - всегда против! Некоторые таковы из-за скверности 
характера, но есть $и$ те, кто этот инструмент используют спечиально, решая ту или иную задачу! Комментарий на канале ОСО, 04.03.2017. Режим доступа: ttps://www.youtube.com/watch?v=ILMf Ed5KCw (дата обращения: 14.02.2018); Этот колплекс называется «Баба Яга против!» Встречается среди народа реального и виртуального, не описан в официальной литературе, не запантетован, однако... Оппонентов с таким синдромом не смуцает наличие квалификации, сертификатов и дипломов у другой сторонь, они будут яростно спорить с врачом о видах пластики грыжевых ворот, хотя, кроме гаражных и в доме, ворот не видели, они будут спорить с музыкантом, утверждая, что скрипка - не струнный и не смычковый инструмент, они растолкуют Евангелие священнику и богослову, а художнику расскажут, как готовить полотно к работе, ибо до этого, он совериенно не имел об этом представления, несмотря на то, что он Заслуженный и Член Союза... Luiza. Сообщение 1, 27.03.2013 // Форум "Sciense". Режим доступа: https://scisne.net/t-274?pg=4 (дата обращения: 14.04.2018).

Именами (Чебураика, Винни-Пух, кот Леопольд, крокодил Гена, кот Матроскин, почтальон Печкин, старуха Шапокляк и др.), приобретшими символические значения, стали называть друзей и недругов. Однако лингвисты не очень спешили признавать за этими единицами право на языковой статус. Во-первых, потому, что сама наука о крылатых единицах сложилась лишь на рубеже XX-XXI вв. Во-вторых, сказывалось традиционное отношение культурной элиты страны к мультипликации как к искусству легковесному, чисто развлекательному.

Первым рискнул поместить два «мультяшных» КЕ в свои двуязычные словари КС известный лексикограф В.П. Берков: Нам не страиен серый 
волк - из песенки поросят, переведённой на русский язык С. Михалковым и использованной в мультфильме 1963 г. «Три поросёнка» режиссёра И. Аксенчука, созданного на основе фильма У. Диснея (Берков 1984. 130); Hy, заяц, погоди!- реплика Волка, персонажа серии мультипликационных фильмов режиссёра В. Котёночкина «Ну, погоди!», с которыми зрители начали знакомиться в 1969 г. (Там же. 141). Одно КВ из мультфильма «Три поросёнка) - Нам не страиен серый волк- попало в «Русско-немецкий словарь крылатых слов» (Афонькин 1985. 152)., опубликованный практически в то же время, что и словари В.П. Беркова.

Немного позднее в «Словаре крылатых выражений из области искусства» (Шулежкова 2003) уже были описаны КВ из 12 мультфильмов: «Антошка» (1968), «Бременские музыканты» (1968), «Винни-Пух идёт в гости» (1971), «Ну, погоди!» (1969), «Крошка Енот» (1974), «Малыш и Карлсон» (1968), «Приключения кота Леопольда» (1975), «Три поросёнка» (1963), «Чебурашка» (1971), «Безумный аэроплан» и «Пароход Вилли» (1928), «Чип и Дэйл спешат на помощь» (1990). А в словаре «Крылатые слова нашего времени», помимо названных выше, автор анализирует эптонимы из анимационных лент «Снежная королева» 1938 г., «Дюймовочка» 1964 г., «Ёик в тумане» 1975 г., «Большой секрет для маленькой компании» 1979 г., «Маугли» 1967-1970 гг., «Козлёнок, который считал до десяти» 1968 г., «Баба Яга против!» 1980 г. (Дядечко 2008). В этих словарях последовательно проводится не только источниковедческий анализ каждой КЕ, но и неукоснительно реализуется принцип лингвокультурологического описания эптонимов с опорой на теоретические исследования авторов. Однако большинство создателей эптографических словарей обходят стороной проблему увлечения носителей русского языка крылатыми словами и выражениями из мультфильмов. Так, в прекрасно изданной энциклопедии «Крылатые слова», в которой уточняется авторство, описывается значение и происхождение $4000 \mathrm{KE}$, читатель вряд ли 
найдёт КС и КВ, восходящие к анимационным картинам, хотя единицы, рождённые кинематографом, представлены в ней достаточно широко [Серов 2003]. То же самое можно сказать о неоднократно переиздававшемся «Словаре современных цитат», где называются источники, авторы и время возникновения 4750 цитат и выражений XX в. из области литературы, истории, политики, науки, кино, эстрады, спорта (Душенко 2002).

Носители русского языка прекрасно осознают изменения, происходящие в национальной культуре, и с удовольствием включают мультипликационный пласт КЕ в лексико-фразеологическую «сетку координат, которую даёт им», по выражению А. Вежбицкой, их «родной язык», чтобы «задействовать» их при выражении своих эмоций, своих чувств. Мало того, как справедливо заметил автор «Словаря крылатых фраз российского кино», сейчас «существует явление, которое условно можно назвать народной интернетлексикографией. В принципе её можно назвать и по-другому: nonлексикография. Основная её характеристика - простота, доходящая "до святости"» (Елистратов 2010. 3-4). В Интернете легко можно отыскать перечни «популярных цитат) из любого мультфильма. Они грешат не только субъективностью отбора и отсутствием семантических и ситуационных описаний употребления приведённых фраз, но и содержат массу неточностей.

Самодеятельное лексикографическое творчество - реакция на отсутствие по-настоящему востребованных и, что не менее важно, доступных словарей с описанием «мультипликационных» КЕ. В значительной мере решить эту проблему мог бы «Словарь крылатых фраз российского кино», опубликованный в 2010 г,, однако он вышел тиражом всего в 5000 экземпляров. В этом словаре, жанр которого автор определил как «русский кинемалогос», каждая популярная киноцитата приводится в своей начальной форме; затем кратко характеризуется её значение; называется фильм, где она прозвучала впервые; указывается ситуация, в которой уместно её 
употребление; описываются интонация или жесты того, кто использует киноцитату в речи. Например:

НЕПРАВИЛЬНО ТЫ, ДЯДЯ ФЁДОР, БУТЕРБРОД ЕШЬ. О ТОМ, что собеседник делает что-л. неправильно, неумело («трое из Простоквашино»). Произносится с «кошачьими» интонациями (Елистратов 2010. 178);

ЛЕТАЕТ... ПАРИТ... НАШ ОРЁЛ! Шутливо о ком-Л., делающем что-л. выдающееся, необычное, демонстрирующем свою силу, умение что-л. делать и т. П. («38 попугаев»). Произносится с нарочитым умилением (Там же. 144);

ДО ПЯТНИЦЫ Я СОВЕРШЕННО СВОБОДЕН. Шутливый ответ на вопрос о том, свободен ли в данный момент говорящий («Винни-Пух идёт в гости») (Там же. 94).

Мультфильмы как источники КЕ и как вид искусства В.С. Елистратовым поставлены в один ряд с фильмами «большого кино». Из 210 кинолент«поставщиков» КС, описанных в его Словаре, 42, то есть пятая часть, - ленты анимационные. Материалы Словаря свидетельствуют о том, что по количеству «порождения» киноцитат лидируют отечественные мультипликационные фильмы. Так, из сериала о деревне Простоквашино (1978-1984) в Словарь включено 46 крылатых фраз, из мультфильма «Падал прошлогодний снег» (1983) - 32, из цикла о крокодиле Гене и Чебурашке (1969-1983) - 30, из сериала о Малыше и Карлсоне (1968-1970) - 27; из мультфильмов «Бременские музыканты» и «По следам бременских музыкантов» (1969-1973) - 25 крылатых фраз. Даже если тщательный лингвокультурологический анализ, сопряжённый с иллюстрированием каждой КЕ добротными примерами, заставит лексикографов скорректировать и сократить количество единиц из Словаря В.С. Елистратова, оставшиеся КЕ, несомненно, также 
будут отражать главную тенденцию в развитии русской национальной культуры - её превращение из литературоцентристской в зрелищецентристскую. Ни русская поэзия, ни русская проза 1960-х - начала 2000-х гг. по охвату аудитории и по продуктивности порождения новых КС и КВ не могут соперничать с кинематографом, неотделимой, хотя и своеобразной, частью которого является мультипликация.

Чем же можно объяснить феномен «языковой продуктивности» детских мультфильмов не только советского прошлого, но и, как показывают наблюдения над состоянием современного анимационного искусства России, постсоветского периода? С самого своего возникновения мультипликация воспринималась, прежде всего, как искусство изобразительное, в котором слово должно было уступить место движению. «Многословие - давняя и довольно распространённая болезнь наших мультфильмов. Между тем изобразительная сторона, представляющая собой главное, ведущее начало выразительности этого искусства, должна быть настолько хорошо и точно разработана, чтобы словесный комментарий был либо вовсе не нужен, либо сведён к минимуму», - можно прочитать в монографии «Волшебники экрана. Эстетические проблемы современной мультипликации» (Асенин 1974. 112). Но оказалось, что российская мультипликация тем и отличается от зарубежной, что в ней гармонично взаимодействует разные виды искусства графика, живопись, музыка и слово. Это, наряду с тематикой, которая черпается в основном из русской классической литературы и собственного фольклора, остросюжетностью, великолепной «закадровой» игрой актёров, этическими и эстетическими установками, соответствующими менталитету россиян, и позволяет специалистам говорить об интеллектуальности лучших советских и современных российских мультфильмов. Это же объясняет популярность КЕ из мультфильмов. 
В извечной борьбе двух тенденций - стремления к обновлению и активного противодействия чрезмерным новшествам, грозящим подорвать устои национального языка, граждане России стихийно выбирают путь обогащения родного языка не за счёт англицизмов, которых в условиях глобализации русские итак освоили достаточно много, а за счёт собственных речевых ресурсов. Пусть социологические исследования свидетельствуют о том, что русские перестали быть самой читающей нацией в мире. Но они не утратили интереса к словотворчеству и к фразеотворчеству: «логоцентризм русской культуры не исчез. Наоборот, наблюдается колоссальная тяга к слову во всех его ипостасях» (Елистратов. 4). Эта тяга к слову отражает специфические национальные черты русской языковой личности, её ментальность, проявляпщуюся в стереотипах поведения. «Особенности национальной культуры, психологии и ментальности отражаются в речи, в системе словоупотребления, придают особенный колорит языковой картине мира» (Сергеева 2012. 11). В книге «Русские: Как мы изменились за 20 лет» автор пишет: «... независимо от возраста русским по-прежнему присущи эмоциональность, страстность, любовь к справедливости, открытость, чуткое восприятие чужих эмоциональных состояний, правдивость и умение строить диалог <..> Несмотря ни на какие катаклизмы, русские так и остались русскими, как и их язык» (Сергеева 2015. 408). Русские по-прежнему склонны к соборности, коллективизму. Они готовы помочь тому, кто попал в беду, ценят остроту ума, любят подтрунивать над собой. И реплики из мультфильмов нередко помогают им выразить всё это нестандартно, в шутливой форме. См., например, КВ Давай бояться вместе; Счастье - это когда у тебя все дома; Ребята, давайте жить дружно!; Пустяки, дело житейское!; Собака бывает кусачей только от жизни собачьей; Всё-таки хорошо, что мы снова вместе! 


\section{Зак.ючение}

Конец XX - начало XXI вB. не случайно называют временем словарного бума. Но до сих пор ещё не создан полный словарь крылатых слов и выражений из мультфильмов. Мы полагаем, что это не должен быть обычный справочник, где интересующая читателя единица сопровождается указанием мультфильма, к которому она восходит. Даже если в подобном справочнике будет дана семантическая характеристика, не подтверждённая примерами употребления КЕ, эта информация всё равно мало что скажет пользователю. Необходим словарь мультимедийного типа, снабжённый поисковой системой, позволяющей найти не только текстовую часть словарной статьи с её обязательными зонами (инициальной, источниковедческой, семантической, стилистической, иллюстративной; отражающей узуальное употребление КЕ и трансформированное, а также описывающей ситуацию, в которой уместно её употребление). Структурно, и содержательно такой словарь должен соответствовать описываемому материалу, и этого можно достичь, если приложить к словарной статье подходящую «картинку» и сделать свободным доступ к фрагменту мультфильма, в котором звучит описываемая фраза.

\section{Литература}

1- Асенин С.В. (1974). Волиебники экрана. Эстетические проблемы современной мультипликации. Москва, Изд-во «Искусетво».

2- Афонькин Ю.Н. (1985). Русско-немецкий словарь крылатых слов: Около 1200 единиц. Москва, Изд-во «Русский язык».

3- Ашукин Н.С., Ашукина М.Г. (1966). Kрылатыле слова. Литературныле изтатьл, образные выражения. 3-е изд. Москва. Изд-во «Художественная литература».

4- Берков В.П. (1980). Русско-норвежский словарь крылатых слов. Москва, Издво «Русский язык».

5- Душенко К.В. (1999). Крьлатье слова и цитатный канон культуры // Культурология: Дайджест. Москва, Изд-во «РАН ИНИОН». С. 39-65. 
6- Дядечко Л.П. (2008). Крылатые слова наиего времени. Толковый словарь. Москва, Изд-во «НТ Пресс».

7- Елистратов В.С. (2010). Крылатые слова российского кино. Москва, Изд-во «АСТ-ПРЕСС КНИГА».

8- Кожевников А.Ю. (2001). Большой словарь: Kрылатье фразы отечественного кино. Санкт-Петербург. «Издательский Дом "Нева"». Москва, Изд-во «ОЛМА-ПРЕСС».

9- Ксензенко Е. (2009). Так ожиеают мультфильмы // НТВ. Программа «Сегодня», 13.04.2009. http://www.ntv.ru/novosti/156556/ (дата обращения: 16.12.2017).

10- Сергеева, А.В. (2012). Русские: стереотипь поведения, традиции, ментальность. Москва, Изд-во «Флинта: Наука».

11- Сергеева А.В. (2015). Русские: Как мы изменились за 20 лет? Москва, Изд-во «ФЛННА: Наука».

12- Серов В.В. (2003). Крылатые слова: Эниииллопедия Москва, Изд-во «ЈокидПресе».

13- Уолш И.А., Берков В.П. (1984). Русско-английский словарь крылатых слов: Около 1900 единии. Москва. «Русский язык».

14- Шулежкова С.Г. (2003). Словарь крылатых выражений из области искусства: Более 1000 крылатых выражений. Москва, Изд-во «Азбуковник», «Русские словари».

\section{Bibliography}

1- Asenin S.V. (1974). Volshebniki jekrana. Jesteticheskie problemy sovremennoj mul'tiplikacii. Moskva, Izd-vo «Iskusstvo».

2- Afon'kin Ju.N. (1985). Russko-nemeckij slovar' krylatyh slov: Okolo 1200 edinic. Moskva, Izd-vo «Russkij jazyk».

3- Ashukin N.S., Ashukina M.G. (1966). Krylatye slova. Literaturnye citaty, obraznye vyrazhenija. 3-e izd. Moskva. Izd-vo «Hudozhestvennaja literatura».

4- Berkov V.P. (1980). Russko-norvezhskij slovar' krylatyh slov. Moskva, Izd-vo «Russkij jazyk».

5- Dushenko K.V. (1999). Krylatye slova i citatnyj kanon kul'tury // Kul'turologija: Dajdzhest. Moskva, Izd-vo «RAN INION». S. 39-65.

6- Djadechko L.P. (2008). Krylatye slova nashego vremeni. Tolkovyj slovar'. Moskva, Izd-vo «NT Press».

7- Elistratov V.S. (2010). Krylatye slova rossijskogo kino. Moskva, Izd-vo «ASTPRESS KNIGA». 
8- Kozhevnikov A.Ju. (2001). Bol'shoj slovar': Krylatye frazy otechestvennogo kino. Sankt-Peterburg. «Izdatel'skij Dom "Neva"». Moskva, Izd-vo «OLMA-PRESS».

9- Ksenzenko E. (2009). Tak ozhivajut mul'tfil'my // NTV. Programma «Segodnja», 13.04.2009. http://www.ntv.ru/novosti/156556/ (data obrashhenija: 16.12.2017).

10- Sergeeva, A.V. (2012). Russkie: stereotipy povedenija, tradicii, mental'nost'. Moskva, Izd-vo «Flinta: Nauka».

11- Sergeeva A.V. (2015). Russkie: Kak my izmenilis' za 20 let? Moskva, Izd-vo «FLINTA: Nauka».

12- Serov V.V. (2003). Krylatye slova: Jenciklopedija Moskva, Izd-vo «Lokid-Press».

13- Uolsh I.A., Berkov V.P. (1984). Russko-anglijskij slovar' krylatyh slov: Okolo 1900 edinic. Moskva. «Russkij jazyk».

14- Shulezhkova S.G. (2003). Slovar' krylatyh vyrazhenij iz oblasti iskusstva: Bolee 1000 krylatyh vyrazhenij. Moskva, Izd-vo «Azbukovnik», «Russkie slovari».

HOW TO CITE THIS ARTICLE

Shulezhkova, S. \& Diadechko, L. (2019). Synthetic Genres of

Art as the Sources of Russian Catchword Units Fund

Enrichment. Issledovatel'skiy Zhurnal Russkogo Yazyka I

Literatury, 13, 83-97.

DOI: 10.29252 /iarll. 13.83

URL: http://journaliarll.ir/index.php/iarll/article/view/46

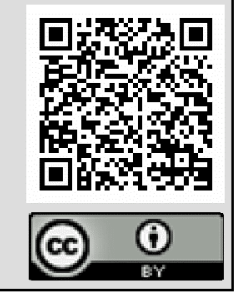




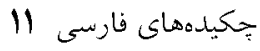

زانرهاى سينتيك هنر به عنوان منابع زايشى تركيبات كنايهاى زبان روسى معاصر

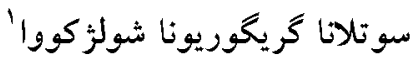

استاد، دانشخاه دولتى كَ. الى. نوسوف ماكَيتيتوكورسك،

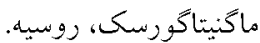

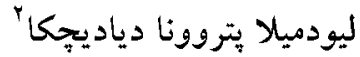

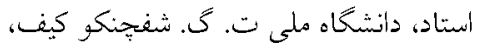

كيف، أوكراين.

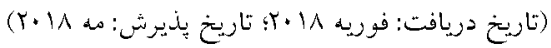

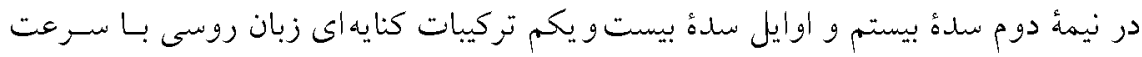

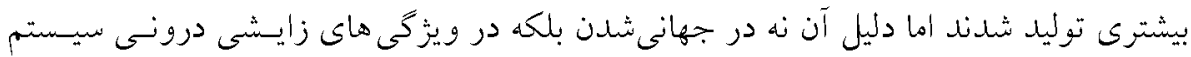

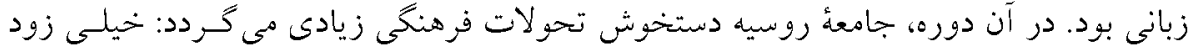

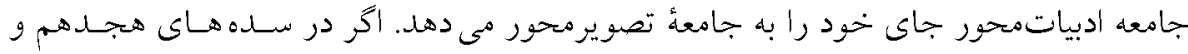

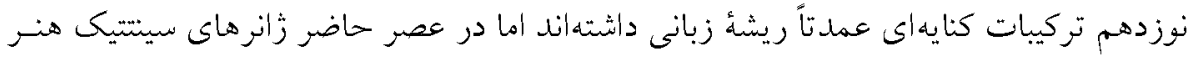

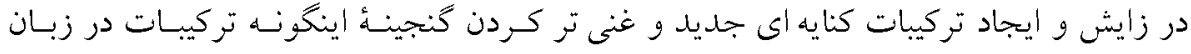

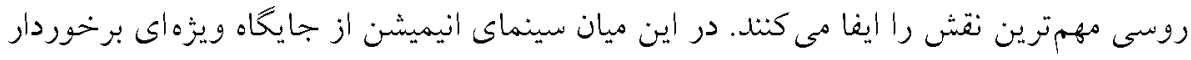

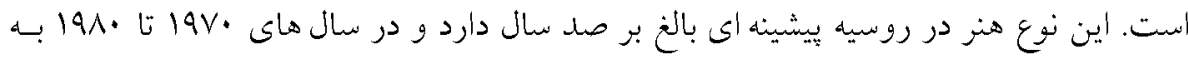

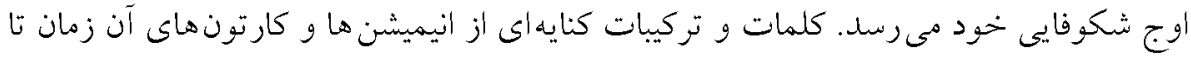

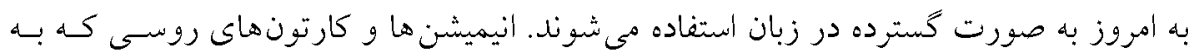

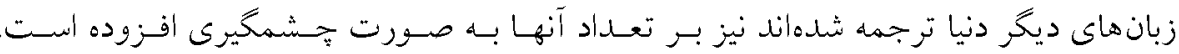

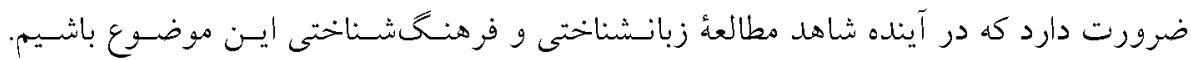

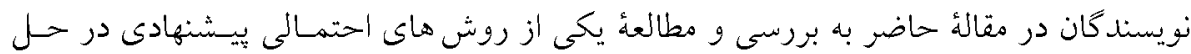

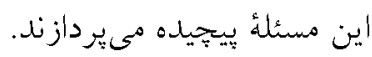

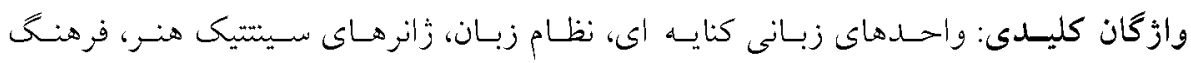
تصويرمحور.

1. E-mail: shulezkova@gmail.com

2. E-mail: eptonim@ukr.net 